\title{
Kandungan Senyawa Saponin pada Daun, Batang dan Umbi Tanaman Binahong (Anredera cordifolia (Ten) Steenis)
}

DOI 10.18196/pt.2016.052.20-24

Umar Hafidz Asy'ari Hasbullah

Program Studi Teknologi Pangan, Fakultas Teknik, Universitas PGRI Semarang, Jalan Sidodadi Timur No 24 Semarnag Jawa Tengah; Email:umarhafidzah@gmail.com

\begin{abstract}
ABSTRAK
Saponin merupakan salah satu senyawa bioaktif yang terdapat dalam tanaman. Saponin mempunyai manfaat bagi kesehatan. Binahong (Anredera cordifolia (Ten) Steenis) telah digunakan oleh masyarakat Indonesia dalam pengobatan, namun penelitian empiris kandungan saponin dalam tanaman binahong belum banyak digali. Penelitian ini bertujuan untuk menentukan kandungan saponin secara kualitatif dan kuantitatif pada bagian daun, batang dan umbi tanaman binahong.Hasil penelitian secara kualitatif dengan Tin Layer Chromatography (TLC) menunjukkan bagian daun, batang dan umbi tanaman binahong saat masih muda maupun tua positif mengandung saponin. Secara kuantitatif kandungan saponin pada daun muda, daun tua, batang muda, batang tua, umbi muda dan umbi tua secara berurutan sebagai berikut 1,37ìg/mg; 2,36ìg/mg; 1,89ig/mg; 1,2ìg/mg; 1,55ig/mg dan 1.35ig/ $\mathrm{mg}$.

Kata Kunci: Binahong, Anredera cordifolia, Saponin
\end{abstract}

\section{ABSTRACT}

Saponin is one of the bioactive compounds present in plants. Saponin has the benefit of human health. Indonesian has been used binahong (Anredera cordifolia (Ten) Steenis) to medicine. However, empirical evidence regarding the content of saponin in binahong not been revealed. This study aims to determine the qualitative and quantitative content of saponins in plants binahong. The results showed that base on Tin Layer Chromatography (TLC) analysis, saponin content in the leaves, stems and tubers binahong both young and old were positive. Quantification results the young leaves, old leaves, young stems, old stems, young tubers and old tubers: $1.37 \mathrm{ig} / \mathrm{mg}, 2.36 \mathrm{ig} / \mathrm{mg}, 1.89 \mathrm{ig} / \mathrm{mg}, 1.2 \mathrm{ig} / \mathrm{mg}, 1.55 \mathrm{ig} / \mathrm{mg}$ and $1.35 \mathrm{ig} / \mathrm{mg}$ respectively. Keywords: Saponin, Anredera cordifolia, Binahong

\section{PENDAHULUAN}

Saponin merupakan salah satu bahan yang menjadi perhatian penting dalam gizi dan pangan (Raju dan Metha, 2008; Cheeke, 1971). Senyawa bioaktif ini mempunyai peranan sebagai antimikrobia dan antijamur (Kayce dkk., 2014), antitumor dan sitotoksik (Feng dkk., 2014; Li dkk., 2014; Noté dkk., 2015) antikanker (Yuan dkk., 2013; Wang dkk., 2013; Tabopda dkk., 2014), ajuvan dan vaksin (Bogoyavlenskiy dkk., 2014), antiinflamasi, immunostimulant, hipokolesterolemik dan antioksidan(Cheeke, 1971; Ng, 2006), fitotoksik (Pérez dkk., 2014) dan memiliki aktivitas hepatoprotektif (Wang dkk., 2015). Baumann dkk.(2000) melaporkan bahwa saponin dapat meningkatkan permeabilitas lipid bilayer untuk mengatur akses antibodi menuju permukaan sitoplasma sel sehingga protein transmembran teragregasi.Saponin juga terbukti memiliki pengaruh yang kuat dalam menginduksi agregasi platetel darah sehingga punya peran dalam hemostatis (Kang dkk., 2014).

Anredera cordifolia (Ten) Steenis dikenal masyarakat Indonesia dengan nama binahong. Tanaman ini telah banyak dipakai sebagai obat tradisional. Masyarakat memakai daun binahong sebagai obat luka pada kulit dan juga luka karena operasi.Kaur dkk.(2014) 
melaporkan pasta daun binahong dapat dipakai dalam menyembuhkan luka. Ekstrak daun binahong memiliki aktivitas analgesik (Yuziani dkk., 2014). Daun binahong juga terbukti mampu meningkatkan fungsi ginjal yang telah rusak (Sukandar dkk., 2011). Hal ini terkait dengan peranannya dalam mereduksi stress oksidatif sel (Sukandar dkk., 2013). Selama ini hanya bagian daun yang banyak dimanfaatkan dalam pengobatan. Penelitian ini bertujuan untuk mengetahui kandungan senyawa saponin secara kualitatif dan kuantitatif pada bagian daun, batang dan umbi tanaman binahong ketika masih muda dan saat sudah tua.

\section{BAHAN DAN METODE}

\section{Bahan}

Sampel daun, batang dan umbi tanaman binahong (Anredera cordifolia (Ten) Steenis) diperoleh dari Balai Pusat Tanaman Obat dan Obat Tradisional (BPTO-OT), Tawangmangu, Karanganyar, Jawa Tengah, Indonesia. Sampel tanaman teridentifikasi oleh Herbarium Bogoriense, no: 1022. Sampel diambil dan langsung dibawa ke laboratorium untuk segera di bersihkan dari kotoran dan dikeringkan dengan pengering kabinet pada suhu $45^{\circ} \mathrm{C}$. Sampel yang telah kering diserbukkan dan dihomogenkan. Sampel yang berupa serbuk dikemas dalam plastik vakum dan disimpan dalam ruang pendingin $\left(4^{\circ} \mathrm{C}\right)$ sampai dianalisis. Saponin white pure standar, vanillin, kloroform, metanol, anisaldehid asam sulfat dari Merch (Darmstadt, Germany).

\section{Analisis Kualitatif Saponin}

Pengujian kualitatif saponin binahong dilakukan dengan Tin Layer Chromatography (TLC) (Sharma dkk., 2012). Sampel (50-100 mg) dimasukkan dalam labu, kemudian ditambahkan $10 \mathrm{ml} 2 \mathrm{~N}$ asam sulfat. Hidrolisis sampel dilakukan selama 30 menit disertai refluk dengan pendingin balik. Sampel didinginkan dan ditambahkan $5 \mathrm{ml}$ kloroform untuk ekstraksi. Fase kloroform diambil dan diuapkan dengan gas nitrogen. Sampel yang telah kering diencerkan hingga 0,5 ml dengan aquades. Sampel (10 il) ditotolkan pada plat silikagel $60 \mathrm{~F}_{254}$. Plat dimasukkan ke dalam chamber yang berisi fase gerak larut kloroform/ metanol (95/5, v/v). Sampel dielusikan hingga batas, kemudian plate dikeringkan. Plate disemprot dengan pereaksi anisaldehid asam sulfat, kemudian dipanaskan pada suhu $110^{\circ} \mathrm{C}$ hingga spot maksimum. Pengamatan dilakukan dibawah sinar visible. Saponin standar digunakan sebagai standar referensi untuk kualifikasi senyawa. Warna spot saponin pada sinar visible menunjukkan biru sampai birukehijauan.

\section{Analisis Kuantitatif Saponin}

Kandungan total saponin ditentukan berdasarkan metode vanillin-asam sulfat (Yang dkk., 2010). Ekstraksi saponin dilakukan dengan etanol pada 100 mg sampel kering. Ekstrak etanol dilanjutkan dengan ekstraksi menggunakan n-butanol. Ekstrak sampel ditambahkan vanillin $(8 \%, \mathrm{w} / \mathrm{v})$ dan asam sulfat $(72 \%, w / v)$. Campuran diinkubasi pada suhu $60^{\circ} \mathrm{C}$ selama 10 menit. Selanjutnya didinginkan dalam ice water bath. Sampel diukur absorbansinya pada panjang gelombang 538 $\mathrm{nm}$. Saponin standar digunakan sebagai standar referensi untuk kuantifikasi. Kandungan total saponin ditunjukkan sebagai saponin standar ekuivalen (ig/mg ekstrak).

\section{HASIL DAN PEMBAHASAN}

Kandungan Kualitatif Saponin Binahong 
Hasil analisa kualitatif dari penentuan kandungan saponin dalam tanaman binahong (Anredera cordifolia) dapat dilihat dalam kromatogram TLC pada Gambar 1. Saponin memberikan warna spot biru-kehijauan. Semua sampel menunjukkan positif mengandung saponin. Nilai Rf saponin terdeteksi dari sampel ditentukan dengan standar saponin (Tabel 1). Data menunjukkan nilai $\mathrm{Rf}$ yang berragam dari 0,45 sampai 0,48. Ukuran spot hasil TLC dari 10 il sampel membentuk eluen senyawa yang terpisah secara melebar pada masing-masing sampel. Hal ini menyebabkan konsentrasi senyawa yang terpisah tidak tinggi dan tidak terfokus pada satu dot. Selain itu terjadi pula sedikit perbedaan jarak tempuh antara senyawa standar saponin dengan sampel. Hal ini diduga terjadi karena perbedaan konsentrasi saponin dari masing-masing sampel.

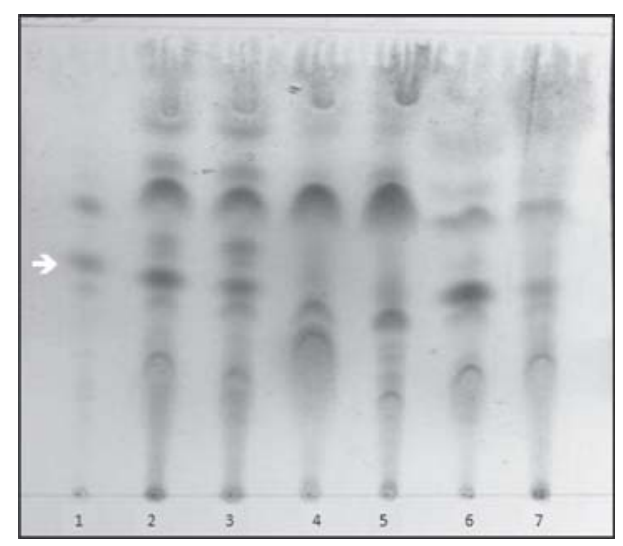

Gambar 1.Kromatogram TLC saponin pada bagian daun, batang dan umbi tanaman binahong. Lane 1: saponin standart, Lane 2: batang muda, Lane 3: batang tua, Lane 4: daun muda, Lane 5: daun tua, Lane 6: umbi muda, Lane 7: umbi tua

\section{Kandungan Kuantitatif Saponin Binahong}

Hasil analisa kuantitatif kandungan saponin dari binahong dapat dilihat pada Gambar 2. Data menunjukkan bahwa secara berurutan kandungan saponin dalam batang muda $(1,88$ ìg/mg), batang tua (1,2 ìg/mg), daun muda(1,37 $\mathrm{ig} / \mathrm{mg})$, daun tua $(2,36 \mathrm{ig} / \mathrm{mg})$, umbi muda $(1,55$ $\mathrm{ig} / \mathrm{mg})$ dan umbi tua $(1,35 \mathrm{ig} / \mathrm{mg})$ tanaman binahong. Astuti dkk. (2011) melaporkan bahwa pada Anredera cordifolia menganndung crude saponin 28,14 mg/g pada daun, 3,65 mg/g pada batang dan 43,15 mg/g pada umbi. Yang dkk. (2010) melaporkan kandungan crude saponin pada pericarp S. mukorossi Gaertn adalah 14,2\% dan kandungan total saponin dalam ekstrak crude saponin sebesar $85 \%(\mathrm{~b} / \mathrm{b})$. Sementara Chen dkk.(2010) melaporkan kandungan crude saponin dalam biji defatting C.oleifera sebesar $8,34 \%$ dan kandungan total saponin dalam ekstrak crude saponin sebesar 39,5\% (b/b). Chen dkk. (2011) melaporkan yield (mg/g) crude saponin ekstrak dari 22 herbal tradisional cina yaitu Ligusticum chuanxiong (33,1), Astragalus membranaceus $(39,7)$, Codonopsis pilosula $(97,4)$, Artemisia capillaries $(121,7)$, Rehmannia glutinosa $(90,8)$, Angelicae dahuricae $(15,4)$, Alisma orientalis (21,9), Scutellaria baicalensis (24,6), Paeonia suffruticosa $(49,2)$, Ligustrum lucidum $(41,9)$, Chrysanthemum morifolium (56,6), Cassia obtusifolia (15,5), Eupatorium fortune $(27,6)$, Euryale ferox (1,6), Glycyrrhiza uralensis $(66,5)$, Coix lacrymajobi (4,4), Pinella ternate (1,2), Radix trichosanthis $(3,1)$, Atractylodes macrocephala $(28,9)$, Radix Puerariae (9,3), Periploca sepium $(81,4)$ dan Poria cocoa $(0,9)$.

Astuti dkk.(2011) melaporkan dalam daun binahong ini mengandung senyawa biokatif saponin triterpenoid and steroid. Kandungan saponin dalam binahong mempunyai manfaat dalam kesehatan manusia dan dapat digunakan sebagai terapi. Yuliani dkk.(2012) juga melaporkan bahwa daun binahong telah diformulasikan dalam gel penyembuh luka. Salasanti dkk.(2014) menyampaikan bahwa dosis letal dari pemberian ekstrak etanol daun 
Tabel 1. Nilai Rf Hasil TLC Deteksi Saponin pada Berbagai Bagian Tanaman Binahong

\begin{tabular}{lllllll}
\hline \multirow{3}{*}{ Parameter } & \multicolumn{2}{l}{ Bagian tanaman binahong } & & & \\
& $\begin{array}{l}\text { Daun } \\
\text { Muda }\end{array}$ & Tua & Matang & Umbi & \\
& Muda & Tua & Muda & Tua \\
\hline
\end{tabular}

binahong untuk pengobatan sebesar $15 \mathrm{~g} / \mathrm{kg}$ berat badan. Ekstrak etanol daun binahong juga terbukti dapat menyembuhkan luka gores pada kulit (Miladiyah dan Prabowo, 2012).

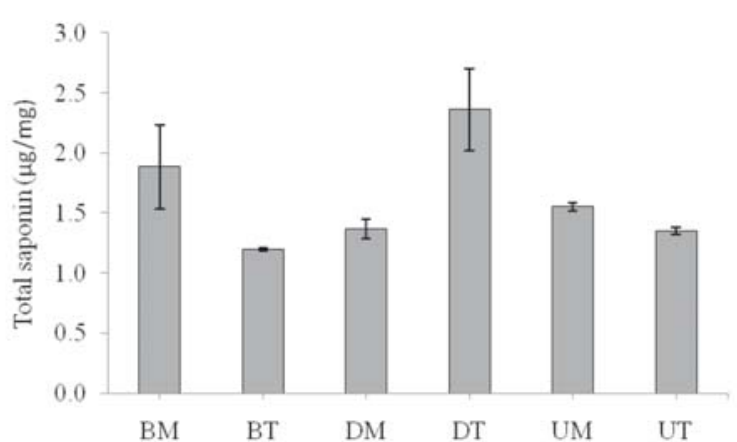

Gambar 2. Total Saponin dari Bagian Batang, Daun dan Umbi Tanaman Binahong. BM: batang muda, BT: batang tua, DM: daun muda, DT: daun tua, UM: umbi muda, UT: umbi tua. Data disajikan dengan Standar Deviasi

\section{SIMPULAN}

Bagian tanaman yang berupa daun, batang dan umbi binahong (Anredera cordifolia) mengandung senyawa saponin. Bagian batang dan umbi tanaman binahong juga dapat digunakan sebagai sumber saponin.

\section{UCAPAN TERIMA KASIH}

Penulis menyampaikan terimakasih kepada LPPT UGM atas fasilitas untuk analisis TLC dan Laboratorium Farmakologi, Fakultas Farmasi UGM atas fasilitas analisis total saponin.

\section{DAFTAR PUSTAKA}

Astuti, S.M., M. Sakinah A.M, R. Andayani B.M dan A. Risch. 2011. Determination of saponin compound from Anredera cordifolia(Ten) Steenis plant (binahong) to potential treatment for several diseases. Journal of Agricultural Science 3(4):224-232.

Baumann, E., G. Stoya, A. Volkner, W. Richter, C. Lemke dan W. Linss. 2000. Hemolysis of human erythrocytes with saponin affects the membrane structure. Acta Histochem 102:21-35.

Bogoyavlenskiy, A. P., P. G. Alexyuk, I. A. Zaitseva, M. S. Alexyuk, N. S. Sokolova dan V. E. Berezin. 2014. Saponin adjuvant for human and veterinary vaccines. Abstracts/Journal of Biotechnology S96,185S:S37-S125.

Cheeke, P. R.. 1971. Nutritional and physiological implications of saponins: a review. Canadian Journal of Animal Science 51:621632.

Chen, Y., C. Yang, M. Chang, Y. Ciou dan Y. Huang. 2010. Foam properties and detergent abilities of the saponins from Camellia oleifera. International Journal of Molecular Sciences 11:4417-4425.

Chen, Y., H. Roan, C. Lii, Y. Huang dan T. Wang. 2011. Relationship between antioxidant and antiglycation ability of saponins, polyphenols, and polysaccharides in Chinese herbal medicines used to treat diabetes. Journal of Medicinal Plants Research. 5(11):2322-2331.

Feng F., X. Xi-Yu, L. Fu-Lei, L. Wen-Yuan dan X. Ning. 2014. Triterpenoid saponins from Patrinia scabra. Chinese Journal of Natural Medicines 12(1):0043-0046.

Kang, L., K. Wua, H. Yu, X. Pang, J. Liu, L. Han, J. Zhang, Y. Zhao, C. Xiong, X. Song, C. Liu, Y. Cong dan B. Ma. 2014. Steroidal saponins from Tribulus terrestris. Phytochemistry 107:182189.

Kaur, G., N. V. Utami dan H. A. Usman. 2014.Effect of Topical Application of Binahong [Anredera cordifolia (Ten.) Steenis] Leaf Paste in Wound Healing Process in Mice Althea Medical Journal 1(1):6-11.

Kayce, P., N. B. Sarikahya dan S. Kirmizigul. 2014. Two novel saponins from Cephalaria davisiana (Dipsacaceae). Phytochemistry Letters 10:324-329.

Li, C., L. Yuan, T. Ji, J. Yang, A. Wang dan Y. Su. 2014. Furostanol saponins from the seeds of Allium cepal.. Fitoterapia 99:5663.

Miladiyah, I. dan B. R. Prabowo. 2012. Ethanolic extract of 
Anredera cordifolia (Ten.) Steenis leaves improved wound healing in guinea pigs. Universa Medicina 31(1):4-11.

$\mathrm{Ng}$, T.B. 2006.Pharmacological activity of sanchi ginseng (Panax notoginseng). Journal of Pharmacy and Pharmacology 58:1007-1019.

Noté, O. P., D. Jihu, C. Antheaume dan D. Guillaume, D. E. Pegnyemb، M. C. Kilhoffer dan A. Lobstein. 2015. Triterpenoid saponins from Albizia boromoensis Aubrév. \& Pellegr. Phytochemistry Letters 11:37-42.

Pérez, A. J., A. M. Simonet, J. M. Calle, E. Pecio, J. O. Guerra, A. Stochmal dan F. A. Macías. 2014. Phytotoxic steroidal saponins from Agave offoyana leaves. Phytochemistry 105:92-100.

Raju, J. dan R. Mehta. 2008. Cancer chemopreventive and therapeutic effects of diosgenin, a food saponin. Nutrition and Cancer 61(1):27-35.

Salasanti, C. D., E. Y. Sukandar dan I. Fidrianny. 2014. Acute and Sub Chronic Toxicity Study of Ethanol Extract of Anredera Cordifolia (Ten.) V. Steenis Leaves. Int. J. Pharm. Pharm. Sci. 6(5):348-352.

Sharma, P.P., N. Kumar, B. Singh, T.K. Bhat. 2012. An improved method for thin layer chromatographic analysis of saponins. Food Chemistry 132:671-674.

Sukandar, E. Y., I. Fidrianny dan L. F. Adiwibowo. 2011. Efficacy of Ethanol Extract of Andrera cordifolia (Ten) Steenis Leaves on Improving Kidney Failure in Rats. International Journal of Pharmacology 7(8):850-855.

Sukandar, E. Y., J. I. Sigit dan L. F. Adiwibowo. 2013. Study of Kidney Repair Mechanisms of Corn Silk (Zea mays L. Hair)Binahong (Andrera cordifolia (Ten.) Steenis) Leaves Combination in Rat Model of Kidney Failure. International Journal of Pharmacology 9(1):12-23.

Tabopda, T. K., A. Mitaine-Offer, C. Tanaka, T. Miyamoto, J. Mirjolet, 0. Duchamp, B. T. Ngadjui dan M. Lacaille-Dubois. 2014. Steroidal saponins from Dioscorea preussii. Fitoterapia 97:198-203.

Wang, S., G. Mab, M. Zhong, S. Yu, X. Xu, Y. Hu, Y. Zhang, H. Wei dan J. Yang. 2013. Triterpene saponins from Tabellae Clinopodii. Fitoterapia 90:14-19.

Wang, Y., L. Zhang, C. Zhang, Y. Liu, D. Liang, H. Luo, Z. Hao, R. Chen dan D. Yu. 2015. Esters of new oleanane-type triterpenoid saponins from Schefflera kwangsiensis. Phytochemistry Letters 11:95-101.

Yang, C., Y. Huang, Y. Chen dan M. Chang. 2010. Foam Properties, Detergent Abilities and Long-term Preservative Efficacy of the Saponins from Sapindus mukorossi. Journal of Food and Drug Analysis 18(3):155-160.

Yuan,W., P. Wang, Z. Zhang, Z. Su dan S. Li. 2013. Triterpenoid saponins from Sesbania vesicaria. Phytochemistry Letters 6:106-109.

Yuliani, S.H., A. Fudholi, S. Pramono dan Marchaban. 2012. The Effect of Formula to Physical Properties of Wound Healing Gel of Ethanolic Extract of Binahong (Anredera cordifolia (Ten) Steenis). Int. J. Pharm. Sci. Res. 3(11):4254-4259.

Yuziani, U. Harahap dan Karsono. 2014. Evaluation of Analgesic Activities of Ethanolic Extract of Anredera Cordifolia (Ten) Steenis Leaf. Int. J. Pharm. Tech. Res. 6(5):1608-1610.

Zhou, B., X. Wei, R. Wang dan J. Jia. 2010. Quantification of the enzymatic browning and secondary metabolites in the callus culture system of Nigella glandulifera Freyn et Sint. Asian Journal of Traditional Medicines 5(3):109-116. 